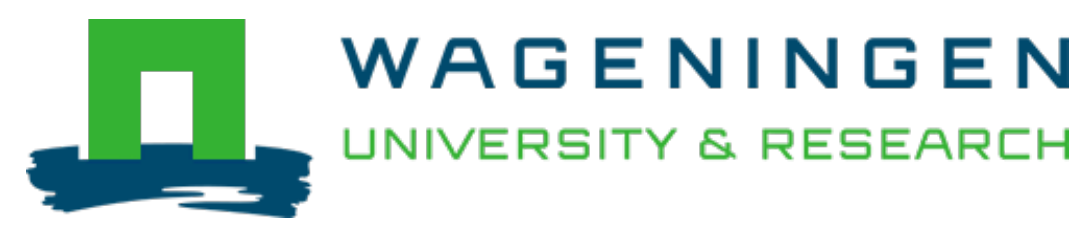

\title{
Quality of farmers' varieties of sorghum and derived foods as perceived by consumers in Benin
}

\author{
Ecology of Food and Nutrition \\ Kayodé, A.P.P.; Adegbidi, A.; Hounhouigan, J.D.; Linnemann, A.R.; Nout, M.J.R. \\ https://doi.org/10.1080/03670240500187302
}

This publication is made publicly available in the institutional repository of Wageningen University and Research, under the terms of article $25 \mathrm{fa}$ of the Dutch Copyright Act, also known as the Amendment Taverne. This has been done with explicit consent by the author.

Article 25 fa states that the author of a short scientific work funded either wholly or partially by Dutch public funds is entitled to make that work publicly available for no consideration following a reasonable period of time after the work was first published, provided that clear reference is made to the source of the first publication of the work.

This publication is distributed under The Association of Universities in the Netherlands (VSNU) 'Article $25 \mathrm{fa}$ implementation' project. In this project research outputs of researchers employed by Dutch Universities that comply with the legal requirements of Article $25 \mathrm{fa}$ of the Dutch Copyright Act are distributed online and free of cost or other barriers in institutional repositories. Research outputs are distributed six months after their first online publication in the original published version and with proper attribution to the source of the original publication.

You are permitted to download and use the publication for personal purposes. All rights remain with the author(s) and / or copyright owner(s) of this work. Any use of the publication or parts of it other than authorised under article $25 \mathrm{fa}$ of the Dutch Copyright act is prohibited. Wageningen University \& Research and the author(s) of this publication shall not be held responsible or liable for any damages resulting from your (re)use of this publication.

For questions regarding the public availability of this publication please contact openscience.library@wur.nl 


\title{
QUALITY OF FARMERS' VARIETIES OF SORGHUM AND DERIVED FOODS AS PERCEIVED BY CONSUMERS IN BENIN
}

\section{A.P. POLYCARPE KAYODE ANSELME ADEGBIDI JOSEPH D. HOUNHOUIGAN} Faculté des Sciences Agronomiques, Université
d'Abomey-Calavi, Cotonou, Bénin

\author{
ANITA R. LINNEMANN \\ M.J. ROBERT NOUT \\ Department of Agrotechnology and Food Sciences, \\ Wageningen University, Wageningen, The Netherlands
}

\begin{abstract}
Culinary and sensory characteristics of sorghum crops and derived foods in northern Benin were investigated using rapid appraisal and quantitative survey methods. Three food categories were identified: pastes, porridges, and beverages. In the main town, all of these are encountered. In other areas, sorghum is mostly consumed as either paste or beverages. The major sensory quality attributes are related to texture, color, and taste. Brown or red sorghum types are generally used, because of food habits, beliefs, and appearance. We distinguished more than 100 farmers' varieties and classified them according to their suitability for the preparation of different sorghum- based foods.
\end{abstract}

KEYWORDS sorghum, paste, porridge, beverage

Financial support provided by Wageningen University through the North-South Interdisciplinary Research and Education Fund (INREF) is gratefully acknowledged. Thanks are also due to Nicolas Bricas (Cirad) and Professor Anke Niehof (Wageningen University) for helpful advice during the design of the questionnaire.

Address correspondence to M.J. Robert Nout, Wageningen University, P.O. Box 8129, Wageningen, 6700, EV, Netherlands. E-mail: rob.nout@wur.nl 


\section{INTRODUCTION}

Sorghum is an important food crop in sub-Saharan Africa and in other semi-arid regions of the world. During the past decades several breeding programs have been conducted on food crops in Africa in view of improving their performance. The primary criteria applied in these programs were mostly based on agronomic characteristics: high yield and tolerance to drought or pests (Badu-Apraku et al., 1995). From a nutritional point of view, the main objective was to improve the protein content of staple crops (Graham et al., 1999). However, many new cultivars were not adopted by the intended users (farmers, processors, consumers). An example is the maize-breeding program in Benin where only $12 \%$ of the area cultivated with maize is devoted to new cultivars in spite of their favorable agronomic characteristics (Koudokpon, 1991). A similar trend is reported in Malawi (Kydd, 1989). The inability of the new cultivars to meet consumers' quality expectations was identified as the major obstacle (Nago, 1997; Koudokpon, 1991; Kydd, 1989; Latrille et al., 1982). Likewise, in cassava cooking, quality (cooking time, taste, and texture of the cooked product) is an important trait that influences the success of new cultivars in some important markets (CIAT, 1993). Nutritional values of foods are important quality aspects for consumers' food security, but they are not the only determinants of food choice. The process of food choice in western societies is well documented. In general, consumers' food preference is directed by quality expectation, quality experience, and credence quality (Grunert, 2002, Darby \& Karni, 1973). Quality expectation is directed by the so-called quality cue, which can be intrinsic (physical properties like texture, color, etc.) or extrinsic (price, brand, advertising claim, retail outlet). Quality expectation is the abstract belief about the quality of a product. Quality experience is based on the actual consumption. The match of quality expectation and quality experience determines consumers' satisfaction (Olivier, 1980, 1993). The credence quality attributes are purely cognitive (Oude Ophuis and Van Trijp, 1995).

Consequently, consumers' quality perception of grains and derived foods needs to be incorporated in breeding programs for successful adoption of improved varieties. Genetic modification can radically affect desirable food quality traits. For example, discoloration of endosperm due to over-expression of $\beta$-carotene is seen as a barrier to adoption for certain food crops (Graham et al., 1999). Each country, 
and in some instances, even different areas within a country, has its own measure of quality (Graham et al., 1999). Quality appears to depend to a great extent on historical, socio-economic, and some crop adaptation factors. Very little documentation is available on consumers' quality preference of African local foods. Studies on yam food quality show the predominance of color, taste, and texture in Benin's yam consumers' food choice (Hounhouigan et al., 2003). Appearance, texture, color, and taste are important quality criteria that determine the choice and consumption of plantain in urban Cameroon (Dury et al., 2002).

This article presents the results of a study to determine the main quality criteria determining choice and consumption of sorghum and sorghum-based foods in Benin. The findings serve to define the scope in terms of consumer preferences, for the optimization of sorghum breeding, cultivation, and processing. In addition, food-processing technologies at household level were identified that warrant further research into the possibilities to achieve an increased content or bioavailability of micronutrients in sorghum-based foods.

\section{METHODOLOGY}

\section{Rapid appraisal investigation}

A rapid appraisal investigation was conducted in Parakou, the main urban town of northern Benin, to identify the current understanding on sorghum and its derived foods by sorghum consumers. It was carried out as an in-depth individual discussion with a sample of 30 subjects from different geographic and ethnic origins. Additional focus group discussions were performed with two groups of farmers and sorghum processors. The items discussed were related to food type and quality criteria, sorghum crops, and processing methods. The information was collected with a tape recorder. The results were used to design a questionnaire for a quantitative survey.

\section{Quantitative survey}

The quantitative survey was conducted in five communities of northern Benin (Figure 1). These were selected on the basis of the importance of sorghum cultivation and their socio-cultural diversity. One hundred and 


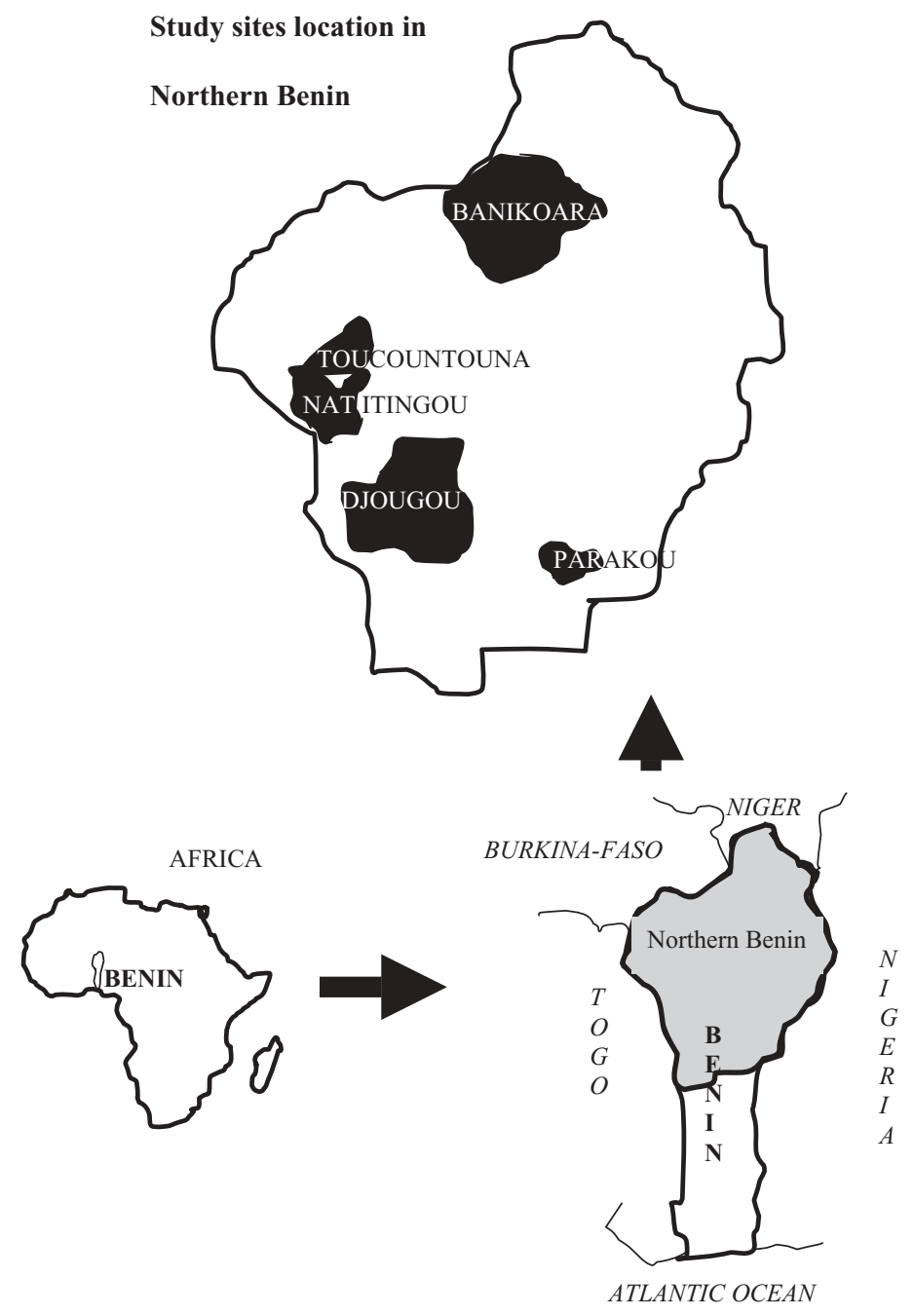

Figure 1. Map of Northern Benin showing the study sites.

eighty households participated in the interviews. They were chosen randomly and differed from each other in terms of standard of living and socio-cultural background. The respondents were either the head of household (male) or the housewife who takes care of food preparation for the family.

The questionnaire included the following aspects: 
- frequency of consumption: frequently $=$ consume the food 4-7 times/ week, regularly $=$ consume the food $2-3$ times/week, occasionally $=$ consume the food 1 time/week and rarely = consume the food less than 1 time/week.

- mode of consumption: time, place of consumption, and type of soup/ ingredient associated with food consumption.

- quality perception: consumers characterized each of the foods in terms of texture or viscoelasticity, taste, color, and smell following a threestep scale ranging from very important to not important. In addition, consumers who judged a quality criterion as very important, were asked to specify which kind of texture (elasticity/extensibility, firmness, viscosity), taste (sweet, neutral, acidic), color (red, brown, white) they preferred. Finally, consumers' opinions about the culinary suitability of sorghum crops were recorded. Data were analyzed using Winstat 2.0 software.

The protocols used for rapid appraisal and quantitative survey were approved by the Faculty of Agronomical Science of the University of Abomey-Calavi; informed consent was obtained from all respondents.

\section{Laboratory analysis}

The physical properties of collected seed samples were determined in the laboratory. Color was measured using a Minolta CR-210 portable chromameter (Illuminant D65 CIE 1976, Minolta, Tokyo, Japan) and the Hunter Lab color coordinate system $L, a^{*}, b^{*}$ values were assessed. $L$ is the whiteness index, $a^{*}$ the red index, and $b^{*}$ the yellow index. The 1000 kernel weight was determined by weighing 100 grains of each sample on a 1/10,000 precision balance and multiplying the obtained value by 10 . The weight was expressed on dry matter basis. All the measurements were performed in duplicate and the average is reported.

\section{Limitation of data}

This study has been conducted at mid-season, when sorghum availability is neither extremely high nor very low. This may have led to some discrepancies. For example, the frequency of consumption and the consumers' perception may vary depending on the availabilty of sorghum. A survey repeated in both availability and shortage periods of sorghum 
could provide insight into changes in consumer behavior according to seasons. Also, the quality criteria affecting the choice of varieties for culinary purposes depend on the kind of derived-food set up by the communities. Thus, in other sorghum producing regions/countries, these criteria may be similar or different depending on the kind of process technologies developed there. The combination of qualitative and quantitative methods in this study helped to capture the real meaning of the consumers attitudes. The qualitative survey was not only useful in adjusting and enhancing the questionnaire, but it also provided a range of information which were very helpful in interpreting the quantitative data. The qualitative tools used, i.e., the individual and focus group discussions, could even have provided more specific information, particularly on sorghum varieties, if methods such as case studies or interviews with key informants would also have been used.

\section{RESULTS AND DISCUSSION}

\section{Predominant sorghum-based foods}

The main sorghum dishes are presented in Table 1. They can be classified into three groups: the pastes (dibou, sifanou, foura), the porridges (koko, sorou, kamanguia), and the beverages (tchoukoutou, chakpalo). Dibou, also called to in Burkina-Faso or oka-baba in Nigeria, is the traditional way of sorghum consumption in most African countries. The preparation of dibou involves cleaning, milling, sieving, and cooking. However, variations exist in the processing method according to region or ethnic group. In some regions (e.g., Parakou) wet cleaning followed by sun drying before milling is practiced by nearly $47 \%$ of the dibou processors interviewed. In other regions (e.g., Natitingou and Djougou), dry cleaning is common. Moreover, nearly $40 \%$ of the processors do not sieve the flour before cooking. These practices may have important implications for the nutritional quality of the dibou. Anti-nutritional factors, such as tannins and phytates, are mainly concentrated in the bran and the aleuronic layer of the grain (Frossard et al., 2000; Beta et al., 1999). Operations such as sieving and wet cleaning of the grain contribute to bran removal. Wet cleaning induces water imbibition of the pericarp and enhances its flexibility and resistance to friction during milling, permitting its separation from the endosperm in the form of large flakes (Brekke \& Kwolek, 1969; Sahay, 1990; Reichert, 1982). Subsequent sieving will therefore be more efficient in removing anti-nutritional factors. 
Table 1. Different sorghum-based foods in Benin

\begin{tabular}{|c|c|c|c|}
\hline Food & $\begin{array}{c}\text { Other Ingredient } \\
\text { Added }\end{array}$ & $\begin{array}{l}\text { Main Unit Process } \\
\text { Operations }\end{array}$ & Description \\
\hline \multicolumn{4}{|l|}{ Paste } \\
\hline Dibou & $\begin{array}{l}\text { Cassava dry } \\
\text { chips, Yam dry } \\
\text { chips }\end{array}$ & Milling, sieving, cooking & $\begin{array}{l}\text { Thick paste eaten with } \\
\text { soup }\end{array}$ \\
\hline Sifanou & Maize & $\begin{array}{l}\text { Germination, milling, } \\
\text { fermentation, cooking }\end{array}$ & $\begin{array}{l}\text { Sweet paste consumed } \\
\text { as porridge }\end{array}$ \\
\hline Foura & Millet & Pounding, steam-cooking & $\begin{array}{l}\text { Steam-cooked paste } \\
\text { consumed as } \\
\text { porridge }\end{array}$ \\
\hline \multicolumn{4}{|l|}{ Porridge } \\
\hline Koko & & $\begin{array}{l}\text { Milling, sieving, fermenta- } \\
\text { tion, cooking }\end{array}$ & Sour porridge \\
\hline Sorou & & Pounding, sieving, cooking & Granulated porridge \\
\hline Kamanguia & Potash & Pounding, sieving, cooking & $\begin{array}{l}\text { Granulated porridge } \\
\text { consumed by } \\
\text { nursing mothers }\end{array}$ \\
\hline \multicolumn{4}{|l|}{ Beverage } \\
\hline Tchoukoutou & & $\begin{array}{l}\text { Soaking, germination, } \\
\text { milling, cooking, } \\
\text { fermentation }\end{array}$ & Alcoholic opaque beer \\
\hline Chakpalo & Maize & $\begin{array}{l}\text { Soaking, germination, } \\
\text { milling, cooking, } \\
\text { filtration, fermentation }\end{array}$ & Alcoholic sweet beer \\
\hline
\end{tabular}

Consequently, it is plausible that consumers of dibou from sorghum that was washed or/and sieved during processing, ingest less anti-nutritional factors.

Dibou is consumed at home, preferably during lunch $(53 \%$ of the interviewed consumers) or dinner (98\%). This meal may be accompanied by okra (Abelmoschus esculentus) or vegetable soup with meat or fish, depending on the wealth of the household. After the preparation of dibou, housewives often keep part of the paste in a clay pot, where it is blended with the powder of baobab fruit or tamarind and left overnight. The acidic paste obtained, named sagnan, is appreciated by adults and infants and consumed as a porridge between meals.

The second type of paste found in the study area is sifanou. It is a sweet and sour paste prepared with germinated sorghum grain to which 
other ungerminated cereals like maize can be added. Sifanou is consumed at midday, mixed with milk and/or ice. Sifanou, also known as gowé in the South of Benin (Nago and Hounhouigan, 1998) is similar to bushera in Uganda and togwa in Tanzania (Mugula et al., 2002; Muyanja et al., 2003).

Foura, the third type of paste in this study, is a slightly sweet paste. After dehulling, sorghum grain is pounded and cooked in boiling water to give a thick dough. The derived paste is sweetened with the juice extracted from the root of baka (Gladiolus psittacinus) and consumed as a porridge with milk or sugar. Foura is generally prepared by the Peuhl and the Haoussa ethnic groups, for whom it is a significant food at wedding days.

Sorghum porridges include koko, sorou, and kamanguia. Koko is a popular sour porridge in Africa. It is similar to ogi porridge in Nigeria and mahewu in South Africa. It contains more than $\mathbf{9 0 \%}$ water (Odunfa, 1985). Sorghum, millet, or maize is used to prepare koko. It is noteworthy that many of Benin's sahelian consumers do not like koko made from maize because of its whiteness. In general, the preparation of koko involves 24 hours of fermentation of a sorghum slurry followed by cooking. In our investigation area, mainly in Parakou, where consumer demand is higher than in other areas of northern Benin, some processors do not use fermentation. In that case, the acidic taste that is normally obtained by fermentation, is produced by cooking the nonfermented sorghum slurry in acidic water obtained, for example, from a neighbor. Such a practice, probably a consequence of urbanization, may be nutritionally less desirable because of the loss of some beneficial effects of fermentation (for example, the degradation of phenolic compounds). Koko is consumed with sugar, honey, or roasted groundnut. Flour from the baobab fruit can also be diluted in koko to obtain an acidic taste.

Sorou is a granulated sorghum porridge obtained by cooking pounded sorghum grains in boiling water (fermented or not). Prior to pounding many processors (about $50 \%$ of the interviewed) proceed to grain washing, whereas others $(21 \%)$ soak the grain for 1 hour to facilitate the dehulling. Sorou is eaten at lunch $(75 \%)$ or breakfast $(41 \%)$. Farmers often consume sorou on the farm at lunch time because it easily satiates and no special relish or soup is needed to consume it. Kamanguia is prepared in much the same way as sorou, except that potash (an alkaline mineral complex consisting mainly of potassium carbonate and believed to stimulate lactation by nursing mothers) is added to the slurry during cooking. 
Tchoukoutou and chakpalo are fermented alcoholic beverages obtained from malted sorghum. Tchoukoutou is an opaque effervescent beer with a considerable solid content, while chakpalo is a more clear beer. Color and taste also differ between both types of local beer. During shortage periods, when sorghum is expensive, maize is added to the sorghum to produce chakpalo. Tchoukoutou is prepared exclusively with sorghum but alternatively, millet is used to brew it. The addition of maize to sorghum in tchoukoutou processing is not appreciated by consumers, because it is believed to cause headaches. Tchoukoutou, which also called dolo in Burkina Faso, is similar to the malawa beer in Uganda and to kaffir beer in South Africa. In fact there are numerous opaque beers in several African countries, each with a local name (Odunfa, 1985).

Chakpalo is prepared in the same way as tchoukoutou except that the filtered final wort is not inoculated and is allowed to undergo a natural fermentation for 2 to 24 hours. Other sorghum products are sodabi (a distilled alcohol from sorghum or maize), woroukou (cooked dehulled sorghum grain), maasa (sorghum fritters), and gnikinou (cooked mixed sorghum and beans).

\section{Importance of sorghum-based food consumption}

The consumption patterns for the different sorghum foods are shown in Table 2. The consumption frequencies are not an indicator of the quantity consumed, but only indicate how often the foods are consumed. Dibou, koko, and sorou are the most frequently consumed sorghum foods.

Table 2. Frequency of consumption of sorghum-based foods (in $\%$ of respondents, $\mathrm{N}=180$ ) in 5 communities in Northern Benin

\begin{tabular}{lrrrc}
\hline Foods & *Frequently & Regularly & Occasionally & Rarely \\
\hline Dibou & 67 & 17 & 5 & 11 \\
Sifanou & 5 & 4 & 11 & 80 \\
Koko & 60 & 6 & 5 & 29 \\
Sorou & 55 & 13 & 9 & 23 \\
Kamanguia & 19 & 8 & 4 & 69 \\
Tchoukoutou & 29 & 6 & 7 & 50 \\
Chakpalo & 8 & 14 & 12 & 74 \\
\hline
\end{tabular}

*frequently: 4-7 times/week; regularly: 2-3 times/week; occasionally: 1 time/week; rarely: less than 1 time/week. 
Tchoukoutou is rarely consumed by $50 \%$ of the respondents. Kamanguia, chakpalo, and sifanou seem to be marginal dishes since they are rarely consumed by more than $70 \%$ of the respondents. For certain foods, the frequency of consumption varies according to sex or ethnic group: kamanguia is mainly consumed by women, especially by nursing mothers, because it is believed to stimulate lactation. In the Bariba community, the best gift to a young mother is a pot of kamanguia. Sorou is mostly consumed by the Bariba and Peuhl, while chakpalo and sifanou are mainly consumed by immigrant ethnic groups (Idatcha and Fon) from the center part of the country, which is also the probable origin of these food processing technologies.

Dibou and sorou are consumed as main dishes and in great quantities. Their processing includes unit operations (milling, pounding, cooking) of limited nutritional impact. Indeed, milling or pounding without dehulling or sieving are of no evident nutritional benefit, whereas cooking is essential to render the product edible, but is reported to decrease the protein digestibility (Eggum et al., 1983). Moreover, many consumers $(>65 \%)$ prefer red or brown sorghum for dibou preparation, which generally is rich in anti-nutritional factors, i.e., polyphenols and phytate (Dicko et al., 2002; Savage, 1989; Nwasike, 1995). Consequently, these foods may be rich in anti-nutritional factors. Phytate and tannins are of particular concern to nutritionists because of their possible adverse effect on digestibility and bioavailability of minerals and proteins. Phytate forms insoluble complexes with essential minerals such as calcium, iron, and zinc at physiological pH levels (Graf, 1986). Phytate may be partially responsible for the widespread mineral deficiencies observed in populations that subsist largely on sorghum and other cereals (Hulse et al., 1980). The role of tannins in human nutrition is due to their proteinbinding capacity, which reduces protein bioavailability.

\section{Important quality criteria for consuming sorghum-based foods}

Quality criteria that are important in choosing sorghum foods, relate to texture, taste, color, and smell. Their importance varies according to the specific food (Table 3). Texture characteristics are considered important by more than $60 \%$ of the consumers of dibou and sorou. Fifty-five percent consider appearance important for tchoukoutou. Taste is perceived as very important for all the foods. Half of the consumers perceived color as a very important characteristic for dibou, koko, tchoukoutou, and chakpalo. 
Table 3. Important quality criteria for consumers of five important sorghum foods in Benin (in \% of $\mathrm{N}$ respondents)

\begin{tabular}{lccccc}
\hline & Dibou & Koko & Sorou & Tchoukoutou & Chakpalo \\
\hline $\mathrm{N}$ & 105 & 62 & 58 & 101 & 30 \\
\hline Texture & $63^{*}$ & 51 & 60 & - & - \\
Appearance & - & - & - & 55 & 43 \\
Taste & $52^{*}$ & 66 & 61 & 66 & 67 \\
Color & $49^{*}$ & 54 & 49 & 55 & 57 \\
Smell & $21^{*}$ & 35 & 28 & 40 & 30 \\
\hline
\end{tabular}

$\mathrm{N}=$ number of people interviewed on the food for the quality aspects.

*Sum $>100$ because several answers were possible.

The smell of the food is not a main concern for the majority of the consumers. However, for tchoukoutou, $40 \%$ of the respondents consider smell an important quality attribute. The detailed criteria for each food are presented below.

\section{Dibou}

Texture is said to be the most important quality attribute of dibou. A good dibou must be elastic/extensible and firm. The taste of the paste should be slightly sweet (67\% of the consumers), but $50 \%$ also likes a paste with a neutral taste. The color preference ranges from pink (84\%) to red $(60 \%)$. Elasticity/extensibility and firmness were also reported as the most important quality criteria for pounded yam and amala, two yam-based pastes (Hounhouigan et al., 2003). Our discussions with housewives reveal that three factors, namely, the sorghum crop, the storage time, and the cooking skill of the housewife, are likely to affect the texture of dibou. A paste prepared with newly harvested sorghum is said to be more elastic/extensible and sweeter than that of sorghum stored for 6 months or longer. When the housewife has to use long-stored sorghum or cannot obtain a suitable sorghum crop to cook dibou, she will add cassava or yam chips to the grain before milling in order to enhance the firmness and the elasticity/extensibility of the paste.

Housewives also explained that the critical stage in dibou cooking is the kneading. An inadequate kneading may result in an inelastic/nonextensible or lumpy paste. The public opinion is that older housewives have good cooking abilities. One of the qualities of a perfect housewife is her 
ability to cook a good dibou, i.e., a firm and elastic/extensible paste. This quality is so important that it is part of the test for a newly married woman. The first dibou she prepares, will be eaten by all the family. The quality of the paste gives an impression of the cooking ability of the newly married wife and an idea about her upbringing.

The color of dibou is so important for some consumers that they systematically reject dibou from maize, because it is white. However, during the period of maize harvesting, we observed some households cooking dibou from maize, possibly because their stock of sorghum was exhausted. Consequently, the way in which consumers judge food quality and how this affects their food choice may change during shortage periods.

Some, mainly older people, argue that white dibou causes diarrhea, but the majority justifies their attachment to pink/red dibou by its supposed richness in nutritious elements or its supposed ability to provide blood. This kind of belief, referred to as a credence quality (Grunert, 2002), was also observed in parts of India and Sri Lanka where red rice is believed to be more nutritious than white (Graham et al., 1999). As early as the 2 nd century A.D., a Greek physician, Galen, urged all young males to eat red foods and drink red liquids to become more sanguine, cheerful, and confident (Pantone, 1986).

\section{Koko}

Texture, taste, and color were said to be the main quality characteristics of koko. A good koko should be viscous but not too much since it is consumed at breakfast or as a complementary infant food. A minority of the consumers $(30 \%)$ prefers a very viscous koko. The combination of a sour taste from the fermentation process and a sweet taste from the addition of sugar or honey is preferred. As for the other sorghum foods, a pink or red color is preferred. The credence quality cues are used here too to justify the color preference (see above). Because of this health-related belief, some housewives see the sorghum koko as the best complementary infant food. Red koko is also believed to fight against malaria. When maize or white sorghum are used to prepare koko, processors always color it with the leaves of dosinsou, which is a type of sorghum especially cultivated for medical purposes and coloration of foods. This processor strategy, common in shortage periods, is particularly used in urban areas to meet quality demands of consumers. 


\section{Sorou}

The first textural quality preferred by sorou consumers is the granulated aspect of the porridge, which means that the grain should not be pounded too finely. About half of the sorou consumers also appreciate a viscous porridge. Sorou is eaten at lunch and as a main dish and therefore must be satiating. A good sorou should also be acidic and/or sweet. A sweet taste is conferred to the porridge by adding sugar or honey. Acidic taste is produced by natural fermentation or addition of baobab fruit powder. The color preference is similar to that of dibou and koko.

\section{Tchoukoutou}

The appearance of tchoukoutou is considered very important by $55 \%$ of the consumers. An opaque beer, i.e., with an appreciable solid content, is perceived as a good product, due to its ability to appease hunger. Others mentioned that the opacity and the effervescent aspect of the beer are indicators of its strength, i.e., its alcohol content. To meet this preference, processors use the appropriate variety or/and an adequate filtering material to obtain the adequate opacity. Generally, a larger mesh basket or bag is used for filtration. The other major quality criterion for tchoukoutou is taste. Consumers always taste the beer before buying. When not satisfied with the taste of the product, they will move on to another seller. All consumers prefer a sour and alcoholic beer. Very few (16\%) like a sweet tchoukoutou, i.e., a non- or slightly fermented product. Some consumers explained that a sweet tchoukoutou is not easy to digest and often causes stomach trouble. A possible explanation could be the presence of pathogenic micro-organisms, which are normally suppressed by a prolonged fermentation process.

Smell is also an important selection criterion when buying tchoukoutou; $40 \%$ of consumers consider it very important. Some consumers claim to be able to infer the overall quality of the beer by its smell. The smell is a quick discriminating quality criterion that these consumers use for a rapid choice of the place of drinking in a beer market with various kinds of tchoukoutou. As mentioned above, the alcohol content is a major criterion for tchoukoutou. A beer with a high alcohol content is preferred by consumers, especially in the Harmattan period when it gets cold. During the survey we observed that some consumers added sodabi (a local distilled alcohol) to tchoukoutou because its strength was not high 
enough for them. According to processors, the starting material and the process conditions affect the alcohol content of tchoukoutou. For example, some sorghum varieties do not yield enough alcohol after processing. Inoculation of the wort or not, as well as the timing of inoculation also affect the alcoholic fermentation. In the Harmattan period, the inoculum is introduced at an early stage when the wort is still a little warm. When the wort is cold, the fermentation process will not take place or only slowly. Pink or red beer is desired, while a white one is rejected. For the consumers, a colored tchoukoutou is the warranty that the beer is really brewed with sorghum, since maize beer is not preferred.

\section{Chakpalo}

Chakpalo is preferred with a fluid consistency and a sweet, slightly acidic taste. The color preference is similar to that of tchoukoutou, i.e., red or pink. Contrary to tchoukoutou (which is exclusively brewed with sorghum), chakpalo can be prepared with maize, especially when sorghum is expensive. In that case, sugar caramel is used to color the beverage to meet consumer preferences.

\section{Important quality criteria for producing sorghum-based foods}

The most important quality criteria for processors in their choice of sorghum crops are presented in Table 4. Color, size, as well as the food yield of the grain are the major selection criteria mentioned by sorghum food

Table 4. Important quality criteria for processors of sorghum (in $\%$ of respondents, $\mathrm{N}=85$ )

\begin{tabular}{lccc}
\hline Characteristics & Very Important & Moderately Important & Not Important \\
\hline Yield of the end-product & 74 & 8 & 17 \\
\hline Color of the grain & 72 & 19 & 8 \\
Size of the grain & 60 & 32 & 8 \\
Ease of germination & 42 & 26 & 32 \\
Ease of fermentation & 18 & 35 & 47 \\
Storability of the grain & 13 & 44 & 44 \\
Ease of milling or pounding & 6 & 15 & 79 \\
Origin of the variety & 4 & 12 & 84 \\
Ease of cooking & 8 & 18 & 62 \\
\hline
\end{tabular}


processors. The ability of the grain to germinate quickly is very important for $42 \%$ of the processors, particularly those who prepare malted foods and beverages. A large number of sorghum phenotypes was recorded in the four communities investigated. Undoubtedly, the same phenotypes may take different names according to locality or ethnicity. So far, no information is available about the genetic characterization of local sorghum varieties to enable their distinction. For the time being, we based our differentiation of the farmers' varieties on the local knowledge of the farmers. This endogenous classification, referred to as the "emic" approach (Harris, 1968), helped to distinguish 24 different farmers' varieties. These 24 are the most popular, i.e., having a popularity index $>5$ (popularity index is the number of consumers who quoted the particular variety). These varieties were characterized for color and 1000-kernel weight.

The suitability of each variety for the preparation of different foods is also reported Table 5. Color is the predominant characteristic that consumers use to distinguish varieties, particularly in the urban area. For example, in Parakou, the majority of consumers belonging to the Bariba ethnic group distinguish only four varieties, namely, dobi swan (brown sorghum), dobi swan sokisoki (red sorghum), dobi pika (cream sorghum), and dobi pika feunfeun (white sorghum). The same is true for people belonging to Dendi and Peuhl ethnic groups. This reveals the loss of knowledge about varieties by these urbanized people. However, rural housewives know well the culinary ability of each variety because of their accrued experiences. The name that producers give to different sorghum varieties is meaningful: it could be the name of the village where the variety originated (e.g., chabicouman), or the name of the farmer who introduced it to the community (e.g., gbango, bio dahu, yacuba), or an indicator of a specific agronomic property (e.g., chassisoya or sakarabokuru $=$ sorghum resistant to Striga), or its morphological appearance (e.g., fissouka $=$ tail of Fissou (an animal), mahi swan $=$ red sorghum). The popularity of some varieties also has to do with their significance for household food security (e.g., natisoya $=$ house sorghum or sorghum of hunger) or their sensory properties (e.g., sotakama = bitter sorghum).

Instrumental color measurements and visual observations helped to identify four groups of farmers' varieties: white grains $(\mathrm{L}>66)$ represented by six varieties, brown grains $\left(a^{*}>8\right)$ containing 13 varieties, red grains $\left(a^{*}>14\right)$ with only one variety, and the yellow grains with high 


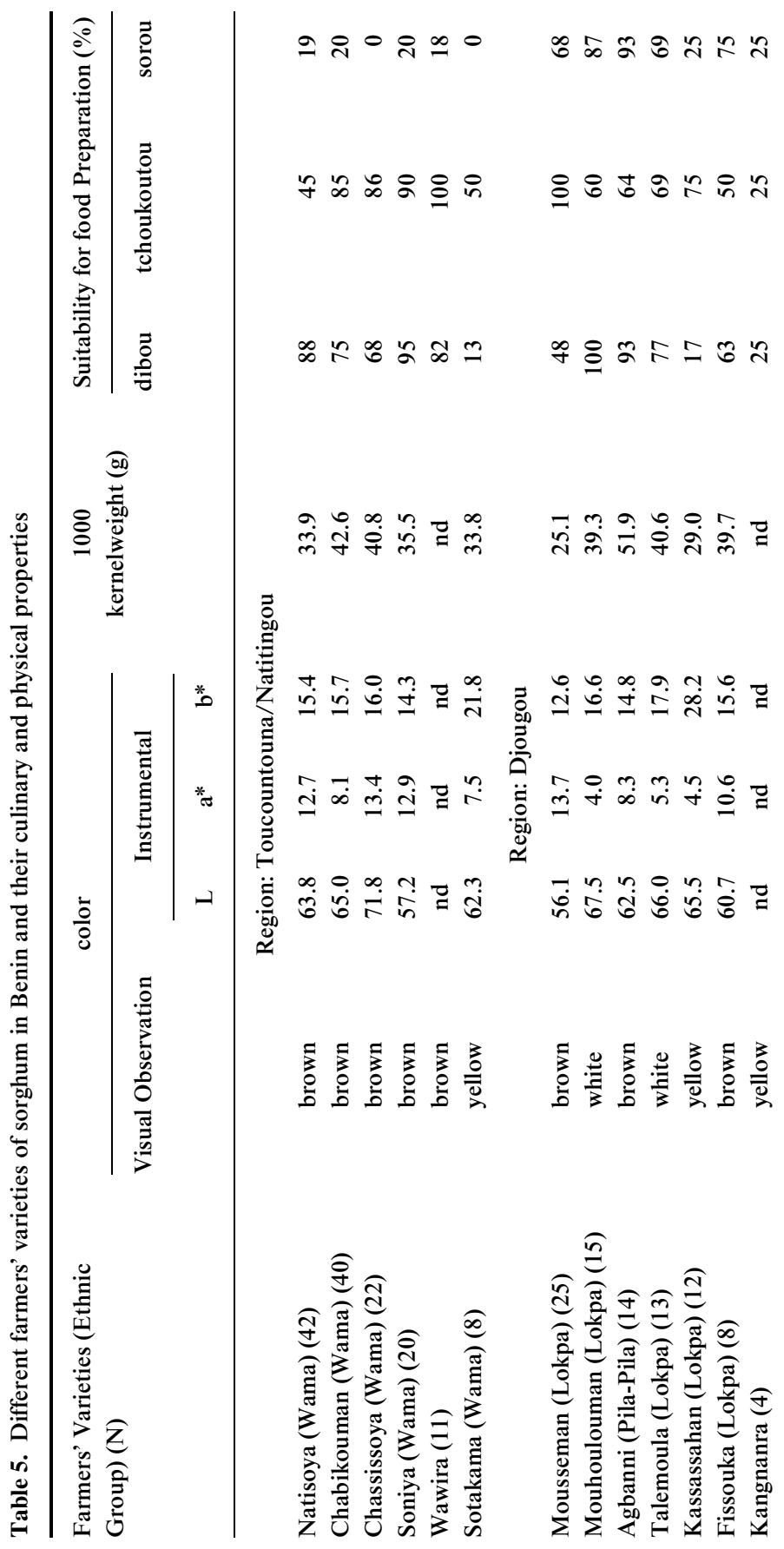




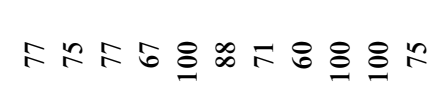

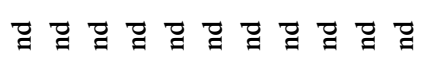

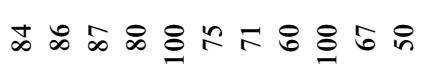

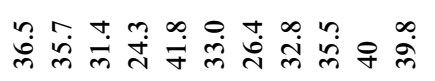

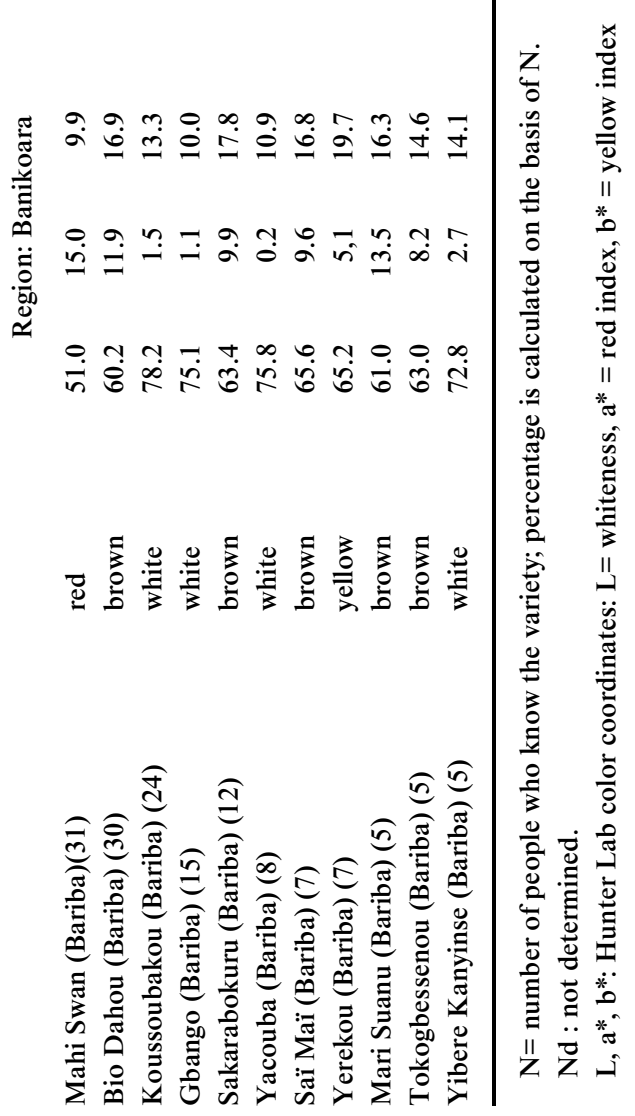


yellow index $\left(b^{*}>19\right)$ represented by four varieties. Possibly the latter are similar, because their characteristics as reported by consumers are quite the same: a bitter taste, yellow color, and very similar appearance of the ear. Most varieties in our study are brown. This agrees well with consumers' preferences.

The 1000-kernel weight $(1000 \mathrm{Kw})$ discriminates the grains as well: large grains $(1000 \mathrm{Kw}>40)$, medium-sized grains (1000 Kw 40-30), and small grains $(1000 \mathrm{Kw}<30)$. These characteristics (color and size) are environmentally dependent and may change according to soil type or/ and rainfall. In the following section, the suitability of different varieties for particular processing purposes is discussed.

\section{Good varieties for sorghum paste and porridge}

In general, all varieties were judged suitable for dibou processing. It is likely that over time farmers selected varieties that met best with consumers' preferences. An exception are the yellow varieties, i.e., sotakama, kangnanra, and kassassahan, which are said to give a bitter dibou. However, a minority of consumers uses them when no other variety is available for their cooking purpose. In that case the sorghum is mixed with other cereals, preferably millet, because of its sweetness (consumer opinion). Some consumers explained their attachment to yellow varieties by the perception that their bitterness helps to fight against malaria. Also mousseman is not very recommended for dibou because it yields less flour after milling and this seems true because it is the smallest seed in size $(1000 \mathrm{Kw}=25)$. However, it is preferred for making sorou or tchoukoutou. Contrary to expectation, the white varieties recorded are also quoted by consumers to be suitable for dibou, even though their color preference for dibou is red or brown. A possible explanation is that the color of the grain is not always a predictor of the color of the derived dibou. According to some consumers, a dibou cooked with some white sorghum grain may turn reddish or even black after cooking. Konouyirou and hannibi are well-known varieties for this color changing property. Our own observation also revealed that dibou paste is always more pink than the flour from which it is made. Such a phenomenon was also found in amala, a dry yam paste (Mestres et al., 2004).

In general, the varieties judged suitable for dibou are also said to be suitable for sorou. 


\section{Good varieties for sorghum beverages}

Discussion with sorghum beer processors revealed that tchoukoutou is one of the most important foods housewives refer to when evaluating the culinary properties of sorghum. Important factors affecting sorghum choice for beer processing include: size and color of the grain, storage period, wort quantity and quality (mainly sugar content), and to a lesser extent the origin of the grain (Table 4).

Preference scores for different varieties according to their suitability for tchoukoutou preparation are shown in Table 5. No scores were recorded for tchoukoutou in the region of Banikoara because sorghum beer is not produced there. The varieties are clustered according to their ability to yield a good quality beer. Over the figures reported, the classification of these varieties also takes into account some qualitative information gained from beer processors. The first category comprises the varieties that are very good for beer brewing, including chabicouma, chassisoya and agbani. Varieties of second choice are: wawira, soniya, mousseman, mouhoulouman, talemoula, and fissouka. Finally the third group is that of varieties unsuitable for brewing.

The varieties of first choice are generally used as a reference to judge the other varieties. They are brown, floury with big grains. They give a high yield of wort with very good properties, i.e., sugary and opaque. Generally, processors use the wort properties as an indicator of the quality of the beer, the sweetness being the major criterion. The sweeter the wort is, the better the beer will be. Another advantage of these varieties is their relatively high availability, presumably due to some favorable agronomic properties. After storage, all of them are still good for brewing as they germinate well. Moreover, they yield well on soils with a low fertility and occasionally are resistant to Striga (only chassisoya).

The varieties of second choice are also good for tchoukoutou processing, but some factors limit their utilization. The white color of some (e.g., mouhoulouman, talemoula) is not favorable for beer processing. These varieties are always mixed with red sorghum to avoid a too white beer. Others are too hard and thus prolong the processing procedure. This is the case with soniya and wawira which require 2-3 days soaking time instead of 1 for germination. Moreover, a lot of inoculum is needed for a quick fermentation of their wort.

The unsuitable varieties for beer production are sotakama, kassassahan, kangnanra, and natisoya. The main shortcoming of the latter is that it yields 
less sugary wort. Another handicap is that it loses its germinative power after a short storage period. However, because it is an early variety some processors used it, just after harvesting, to produce a beer of "bad quality" as they say. The other yellow varieties are bitter in taste and are rather used as hops would be used in lager beer to confer bitterness to the beer. For this purpose, grains are either crushed with the malt or the ears are immersed in the wort during cooking. Other processors grind them after the grain is roasted. The flour obtained is then stored and added to the wort during cooking. Kangnanra is used more for medical purposes. The ear is immersed in boiling water, resulting in an anti-malarial infusion.

\section{CONCLUSION}

This investigation revealed differences in farmers' sorghum varieties in terms of their physical and culinary properties. Sorghum is processed in different ways to yield various foods including pastes, porridges, and beverages. Perception of sorghum quality is related to both the raw grain and the foods these grains will yield after processing. The way sorghum is processed includes unit operations (dehulling, cooking, fermentation, germination) of beneficial nutritional impact. However, foods of high frequency of consumption include few of these operations in their preparation method. Color and size, as well as the quality of the food the grain will yield, determine the choice of sorghum variety by the processors. The texture is the most important quality attribute of the foods consumed as a main meal (dibou and sorou), color is the most important quality characteristic for porridges and beverages, while taste is significant for all sorghum foods. Farmers' management of the diversity found in sorghum varieties responds well to consumers' preferences. Farmers selected and maintained a collection of varieties in which several foodrelated characteristics are present. Of the 24 varieties reported, the majority, namely, $58 \%$, are brown or red. This agrees well with consumers' preferences. Most varieties deliver foods of high quality, while a few are of poor culinary quality but still find their place in the cropping system, probably because of the role they play in household food security (early varieties), or because of their importance as food additives or as medicinal plants. This diversity fits well with the environmental constraints in the sense that it includes at the same time varieties of desired food quality and of particular agronomic properties, like striga resistant 
varieties (chassissoya, sakarabokuru), or early-maturing varieties (natisoya, bio-dahu, mousseman). Interestingly, each community maintained such varieties in their collection. This, together with the fact that these varieties are among the most popular in each area demonstrates their strategic role for food security. Therefore, policies and measures planned for the improvement of sorghum should take the genetic diversity of food crops into account and use this in the same way as farmers do (Negash and Niehof, 2004). In addition to the agronomic and nutritional criteria, such improvement programs must consider consumer quality preferences to breed new varieties that provide paste, porridges, and beverages with adequate color, texture, and taste.

This research describes consumers' and processors' opinions on sorghum and sorghum-based foods. Further research is required to investigate the role of socio-economic variables in sorghum food quality preferences and consumption patterns. In the ongoing process of optimization, the outcome of this study will contribute to define the boundaries for possible changes with respect to consumer preferences. The influence of the variation in local processing methods on the nutritional value of the derived foods will be established with a focus on the micronutrient content and anti-nutritional factors. Important aspects in this respect are the duration of cooking, the sieving of the flour for dehulling, the fermentation and the germination processes. Biological identification of the farmers' varieties will also be performed and reported.

\section{REFERENCES}

Badu-Apraku, B., A.E. Okoruwa, J.G. Kling, and S.K. Kim (1995). Improvement of maize genotypes with appropriate quality characteristics for industrial processing and use. In J. M. Menyonga, B. Taye, C.C. Nwasike, P. M. Sedego, and A. Tenkouano (Eds.) Processing and Industrial Utilization of Sorghum and Related Cereals in Africa. Proceeding of the OAU/STRC-SAFGRAD Regional Symposium, Ouagadougou, Burkina-Faso, 22-26, November 1993, pp. 247-272.

Beta, T., L.W. Rooney, L. Marovatsanga, and J.R.N. Taylor (1999). Phenolic compounds and kernel characteristics of Zimbabwean sorghums. Journal of the Science of Food and Agriculture, 79, 1003-1010.

Brekke, O.L., and W.F. Kwolek (1969). Corn dry-milling: Cold-tempering and degermination of corn of various initial moisture content. Cereal Chemistry, $46,545-559$. 
Centro Internacional de Agricultura Tropical (CIAT) (1993). Cassava Program Annual Report. Working document 146. CIAT, Cali, Colombia, p. 325.

Darby, M.R., and E. Karni (1973). Free competition and the optimal amount of fraud. Journal of Law and Economics, 16, 67-88.

Dicko, M.H., R. Hilhorst, H. Gruppen, A. Traore, C. Laane, W.J.H. Van Berkel, and A.G.J. Voragen (2002). Comparison of content in phenolic compounds, polyphenol oxidase and peroxidase in grains of fifty sorghum cultivars from Burkina Faso. Journal of Agricultural and Food Chemistry, 50, 3780-3788.

Dury, S., N. Bricas, J. Tchango-Tchango, L. Temple, and A. Bikoi (2002). The determinants of urban plantain consumption in Cameroon. Food Quality and Preference, 12, 269-279.

Eggum, B.O., L. Manowar, K.E.B. Knudsen, L. Munch, and J. Axtell (1983). Nutritional quality of sorghum and sorghum foods from Sudan. Journal of Cereal Science, 1, 127-137.

Frossard, E., M. Bucher, F. Machler, A. Mozafar, and R. Hurrell (2000). Potential for increasing the content and bioavailability of $\mathrm{Fe}, \mathrm{Zn}$ and $\mathrm{Ca}$ in plant for human nutrition. Journal of the Science of Food and Agriculture, 80, 861-879.

Graf, E. (1986). Chemistry and application of phytic acid: An overview. In E. Graf (Ed.) Phytic Acid: Chemistry and Application. Minneapolis, MN: Pilatus Press, pp. 1-21.

Graham, R., D. Senadhira, S. Beebe, C. Iglesias, and I. Monasterio (1999). Breeding for micronutrient density in edible portion of staple food crops: Conventional approaches. Field Crop Research, 60, 57-80.

Grunert, K.G. (2002). Current issues in the understanding of consumer food choice. Trends in Food Science \& Technology, 13, 275-285.

Harris, M. (1968). The Rise of Anthropological Theory. New York: Thomas Y. Crowell Company.

Hounhouigan, D.J., A.P.P Kayodé, N. Bricas, and C.M. Nago (2003). Les caractéristiques culinaires et organoleptiques des ignames recherchées en milieu urbain au Bénin. Annales des Sciences Agronomiques du Bénin, 4, 143-160.

Hulse, J.H., E.M. Laing, and D.E. Pearson (1980). Sorghum and Millets: Their Composition and Nutritive Value. London: Academic Press.

Koudokpon, V. (1991). Pourquoi les variétés améliorées de maïs ne sont-elles pas largement adoptées par les paysans? Bulletin de la Recherche Agronomique du Bénin, 2, 6-9.

Kydd, J. (1989). Maize research in Malawi: Lessons from failure. Journal of International Development, 1, 112-144.

Latrille, E., A. Issifou, A. Agboh (1982) Projet de développement rural de la Région Maritime. Recherche agronomique d'accompagnement. Document IRAT/MDR- Togo. 
Mestres, C., S. Dorthe, N. Akissoé, and J. Hounhouigan (2004). Prediction of sensorial properties (colour and taste) of amala, a paste from yam flour of West Africa, through flour biochemical properties. Plant Foods for Human Nutrition, 59, 93-99.

Mugula, J. K., S.A.M. Nnko, J.A. Narvhus, and T. Sorhaug (2002). Microbiological and fermentation characteristics of Togwa, a Tanzanian fermented food. International Journal of Food Microbiology, 80, 187-199.

Muyanja, C.M.B.K., J.A. Narvhus, J. Treimo, and T. Langsrud (2003). Isolation, characterisation and identification of lactic acid bacteria from bushera: A Ugandan traditional fermented beverage. International Journal of Food Microbiology, 80, 201-210.

Nago, C.M. (1997). La transformation alimentaire traditionnelle du maïs au Bénin: Détermination des caractéristiques physico-chimiques des variétés en usage; relations avec l'obtention et la qualité des principaux produits dérivés. Thèse de Doctorat d'Etat, Université Paris 7-Denis Diderot, UFR de Biochimie, 201pp.

Nago, C.M., and D.J. Hounhouigan, (1998). La transformation alimentaire traditionnelle des céréales au Bénin. Les publications du CERNA, FSA/UAC, 152 pp.

Negash, A., and A. Niehof (2004). The significance of Enset culture and biodiversity for rural household food and livelihood security in southwestern Ethiopia. Agriculture and Human Values, 21, 61-71.

Nwasike, C.C. (1995). Improvement of sorghum genotypes with appropriate physiological traits for industrial processing and use. In Menyonga, J.M., B. Taye, C.C. Nwasike, P.M. Sedego, and A. Tenkouano (Eds.) Processing and Industrial Utilization of Sorghum and Related Cereals in Africa. Proceedings of the OAU/STRC-SAFGRAD Regional Symposium, Ouagadougou, Burkina-Faso, 22-26 November, 1993, pp. 273-277.

Odunfa, S.A. (1985). African fermented foods. In Wood, B.J.B. (Ed.) Microbiology of Fermented Foods. London: Elsevier Applied Science, pp. 167-195.

Olivier, R.L. (1980). A cognitive model of the antecedents and consequences of satisfaction decisions. Journal of Marketing Research, 17, 460-469.

Olivier, R.L. (1993). Cognitive, affective, and attribute bases of the satisfaction response. Journal of Consumer Research, 20, 418-431.

Oude Ophuis, P.A.M., and H.C.M. Van Trijp (1995). Perceived quality: A market driven and consumer-oriented approach. Food Quality and Preference, 6, 177-183.

Pantone (1986). Fun foods. In Color News. Woodland Hills, CA: Pantone Color Institute, 1(2), p. 3.

Reichert, R.D. (1982). Sorghum dry milling. In Sorghum in the Eighties, Proceedings of the International Symposium on Sorghum, 2-7 November 1981, Patancheru, AP, India (Vol. 2). International Crops Research Institute for the Semi-Arid Tropics (ICRISAT), Patancheru, AP, India, pp. 547-564. 
Sahay, K.M. (1990). Evaluation of a general purpose abrasive mill for pearling of coarse cereals and dehusking of pulses. International Journal of Food Science and Technology, 25, 220-225.

Savage, G.P. (1989). Influence of tannin binding substances on the quality of yellow and brown sorghum. Nutrition Reports International, 39, 359-366. 